\title{
Undergraduate Laboratory Experience for Ceramics
}

\author{
Mohamed N. Rahaman, William G. Fahrenholtz \\ Department of Ceramic Engineering \\ University of Missouri-Rolla
}

\begin{abstract}
An appreciation for experimental work and the development of laboratory skills are essential parts of undergraduate materials education. To develop effective laboratory courses in materials, the unique characteristics and properties of ceramics must be considered. Normally, ceramics cannot be produced by the methods commonly used for metals and polymers because ceramics are more refractory and brittle than other materials. Ceramics are commonly fabricated by compacting and sintering particulate starting materials. At the University of Missouri-Rolla (UMR), ceramics education is concentrated in the Department of Ceramic Engineering. UMR has an integrated, four-semester laboratory sequence at the sophomore and junior levels designed to provide the specialized training needed for the production of ceramics. The laboratory exercises emphasize a hands-on approach for the students and topics include the use of equipment, selection of raw materials, choice of processing and characterization methods, and statistical design of experiments. The coordination of experiments with topics in other lecture courses is an important part of the undergraduate program. The sophomore and junior classes also provide the necessary foundation for the senior level laboratory courses, a two-semester capstone Senior Design course and a property measurement laboratory.
\end{abstract}

\section{Introduction}

Over the last twenty years, Ceramic Engineering education has been transformed by the emergence of multi-disciplinary materials departments. At several universities, this has resulted in the merging of previously separate departments specializing in metals or ceramics into a single unit that often includes programs in polymers and electronic materials. The new department may be known as Materials Science and Engineering, Materials Engineering, or simply Materials. Examples of merging large, well-established departments include the Ohio State University and the University of Illinois at Urbana-Champaign. More recently, Ceramic Engineering departments at Rutgers University, Alfred University and Clemson University have incorporated a materials component into their ceramics programs. Currently, UMR is the only university where ceramics education and research are housed in a specialized Department of Ceramic Engineering. The predominant situation is, therefore, for ceramics to be taught as part of an undergraduate materials curriculum.

Because the application of engineering principles to problems in materials involves a significant amount of experimental work, it is important that undergraduate students develop an appreciation for laboratory practice. Furthermore, it is important that students learn and refine 
laboratory skills in order to perform effectively in their future careers in industry or academia. This paper outlines the undergraduate laboratory program in Ceramic Engineering at UMR. A coordinated series of laboratory classes has been developed to provide students with a practical background to complement the knowledge that they acquire in lecture courses. A summary of the laboratory courses is given in Table 1. It should be pointed out that the academic schedule at UMR is based on the semester system with courses offered in Fall and Winter terms.

Table 1: Laboratory courses in Ceramic Engineering at the University of Missouri-Rolla.

\begin{tabular}{|l|l|l|}
\hline \multicolumn{1}{|c|}{ Year } & \multicolumn{1}{|c|}{ Semester } & \multicolumn{1}{c|}{ Course Title } \\
\hline Sophomore & $\begin{array}{l}\text { Fall } \\
\text { Winter }\end{array}$ & $\begin{array}{l}\text { Ceramic Materials Characterization I } \\
\text { Ceramic Materials Characterization II }\end{array}$ \\
\hline Junior & Fall & $\begin{array}{l}\text { Ceramic Processing } \\
\text { Statistical Design of Experiments } \\
\text { Microstructural Characterization and Design }\end{array}$ \\
& Winter & $\begin{array}{l}\text { Senior Design I } \\
\text { Properties of Ceramics } \\
\text { Senior Design II }\end{array}$ \\
\hline Senior & Fall & \\
& Winter & \\
\hline
\end{tabular}

One of the differences between a traditional Ceramic Engineering curriculum and that of a multidisciplinary Materials department is the emphasis on laboratory classes. This difference is highlighted by comparing Tables 1 and 2 . The laboratory courses within the baccalaureate degree program in the Materials Science and Engineering department at the University of Illinois at Urbana-Champaign (UIUC) are listed in Table 2. The UIUC curriculum is typical of a Materials department. Notice that only the two junior-level laboratories are required, the senior labs are technical electives. In addition, many of the laboratory exercises are run as demonstrations, not as hands-on experiments.

Table 2: Laboratory courses in Materials Science at the University of Illinois at UrbanaChampaign.

\begin{tabular}{|l|l|l|}
\hline \multicolumn{1}{|c|}{ Year } & \multicolumn{1}{|c|}{ Semester } & \multicolumn{1}{c|}{ Course Title } \\
\hline Sophomore & & None offered \\
\hline Junior & $\begin{array}{l}\text { Fall } \\
\text { Winter }\end{array}$ & $\begin{array}{l}\text { Materials Characterization } \\
\text { Materials Properties }\end{array}$ \\
\hline Senior & Fall/Winter & $\begin{array}{l}\text { Ceramics processing lab (elective) } \\
\text { Metals lab (elective) } \\
\text { Polymers characterization lab (elective) } \\
\text { Electronic materials lab (elective) }\end{array}$ \\
\hline
\end{tabular}

Structurally, ceramics are either amorphous (e.g., glasses) or crystalline. As with metals, the difficulty and expense of growing single crystals means that most crystalline ceramics are actually polycrystalline; they are made up of a large number of small crystals or grains separated 
from one another by grain boundaries. However, common metallurgical fabrication routes based on casting and deformation cannot normally be used to produce polycrystalline ceramics. Most practical ceramics have high melting points, above $1500^{\circ} \mathrm{C}$, and some decompose prior to melting making control of the microstructure difficult during solidification processing. In addition, brittle ceramics cannot normally undergo deformation processing (e.g., rolling) to achieve the required geometry and microstructure. The most efficient method for producing polycrystalline ceramics is the compaction and sintering of fine particulate starting materials. The ability to control the microstructure of sintered ceramics is vital because the microstructure determines the engineering properties. Although powder processing is an important fabrication route for metals, alongside other, equally important routes such as casting and deformation processing, it is, by far, the dominant fabrication route for polycrystalline ceramics.

Particle characteristics and forming methods are important factors in microstructure development. Knowledge of the key experimental variables for each stage of the fabrication route is important. In the following sections, the basic features of UMR's four-semester laboratory sequence at the sophomore and junior levels are described. The discussion focuses on the principles, objectives and methodology of the classes. The sophomore and junior labs build the knowledge and skills base so those students can successfully complete a senior-level design laboratory. Senior Design acts as a capstone. Students must draw on the experimental skills from their laboratory courses and fundamental knowledge presented in lecture courses to successfully complete a yearlong research project.

\section{Sophomore Level Laboratories}

At UMR, the sophomore laboratories are the first exposure the students get to Ceramic Engineering practice. The experiments give the students a broad introduction to the fundamentals of measurement techniques, characterization methods, and processing routes. The basic elements of the experiments are summarized in Tables 3 and 4.

First semester sophomores are enrolled in two Ceramic Engineering lecture classes at the same time as the laboratory course described in Table 3. One is crystallography in which the symmetry and structure of crystalline materials are explored. This course compliments material covered in the density measurement and sintering laboratories, especially the calculation of theoretical density. The other lecture course is a survey that summarizes the important processing techniques, uses, markets, and applications of ceramics. Together, these courses introduce the students to the importance of processing-structure-property relations in ceramics.

During the second semester of the sophomore year, the students only have one lecture course in their major, an introduction to the structure and properties of glassy materials. Laboratory topics that compliment that course include vitrification during firing and glazing of clay-based ceramics, viscosity, x-ray diffraction, glass forming methods, crystallization of glasses, and measurement of refractive index. 
Table 3: First semester sophomore experiments in Ceramic Engineering at UMR.

\begin{tabular}{|l|l|}
\hline \multicolumn{1}{|c|}{ Experiment } & \multicolumn{1}{|c|}{ Principles and Objectives } \\
\hline Density Measurements & $\begin{array}{l}\text { Density of liquids and powders by pycnometry. Density of porous } \\
\text { and dense ceramics using liquid immersion (Archimedes } \\
\text { method). Open vs. closed pores. }\end{array}$ \\
\hline $\begin{array}{l}\text { Furnaces and Temperature } \\
\text { Measurements }\end{array}$ & $\begin{array}{l}\text { The operation of programmable laboratory furnaces. Fabrication } \\
\text { of thermocouples. The use of thermocouples, pyrometric cones, } \\
\text { and pyrometers for accurate temperature measurements. }\end{array}$ \\
\hline Raw Materials & $\begin{array}{l}\text { The collection of ceramic raw materials (e.g., clay, sandstone, and } \\
\text { limestone) from nearby mineral deposits. The importance of } \\
\text { naturally occurring raw materials in the production of ceramics. }\end{array}$ \\
\hline Comminution & $\begin{array}{l}\text { Comminution in mortar and pestle or ball mill. Influence of the } \\
\text { key parameters (e.g., hardness of the raw material, energy input, } \\
\text { and milling time) on grinding efficiency. }\end{array}$ \\
\hline $\begin{array}{l}\text { Particle Size Distribution by } \\
\text { Sieve Analysis }\end{array}$ & $\begin{array}{l}\text { Particle classification by sieving. Techniques for reporting the } \\
\text { particle size distribution. Sampling methods. }\end{array}$ \\
\hline $\begin{array}{l}\text { Powder Compaction by Die- } \\
\text { Pressing }\end{array}$ & $\begin{array}{l}\text { Experience in the most widely used method for consolidating } \\
\text { ceramics. Pressing of a fine oxide powder (e.g., titanium oxide) in } \\
\text { a die to produce cylindrical pellets. The effect of binder additions } \\
\text { and compaction pressure on pellet density. }\end{array}$ \\
\hline Sintering & $\begin{array}{l}\text { Die-pressed pellets are sintered in a furnace to investigate the } \\
\text { effects of green density, sintering temperature and time. Requires } \\
\text { the techniques of density measurement, furnace operation, and } \\
\text { temperature measurement from earlier experiments. }\end{array}$ \\
\hline
\end{tabular}

III. Junior Level Laboratories

The useful properties of ceramics, whether electrical, mechanical, or optical, depend strongly on microstructure. Ceramic processing, which consists of powder processing, forming, and heat treatment, is the key to developing desirable microstructures in ceramics. The first semester of the junior level laboratories is devoted to processing of ceramics while the second semester is devoted to microstructural characterization and microstructural design. The objective is to use the experience provided by the sophomore laboratories to develop skills in the control of microstructure.

First Semester Junior Experiments in Ceramic Engineering at UMR:

The experiments can be classified into four broad areas of powder processing: (1) synthesis of powders, (2) preparation and characterization of particulate suspensions, (3) forming, and (4) sintering. The main elements of the experiments are outlined below.

1. Synthesis of Powders

The underlying principles that control the synthesis of ceramic powders are investigated. The synthesis methods complement the mechanical method, comminution, that was previously studied in the sophomore laboratories. Three methods of powder synthesis are explored: (a) 
Table 4: Second semester sophomore experiments in Ceramic Engineering at UMR.

\begin{tabular}{|c|c|}
\hline Experiment & Principles and Objectives \\
\hline Plaster of Paris Molds & $\begin{array}{l}\text { Processing/structure relationships for plaster of Paris. Plaster } \\
\text { molds for slip casting are fabricated. }\end{array}$ \\
\hline Slip Casting & $\begin{array}{l}\text { Clay-based ceramics are formed by slip casting. Slip preparation, } \\
\text { rheology, casting time, and drying are studied. }\end{array}$ \\
\hline Extrusion & $\begin{array}{l}\text { A moist particulate ceramic mixture is extruded. The effect of } \\
\text { composition and other parameters are investigated. }\end{array}$ \\
\hline $\begin{array}{l}\text { Firing of Clay-Based } \\
\text { Ceramics }\end{array}$ & $\begin{array}{l}\text { Clay-based ceramics formed by slip casting and extrusion are } \\
\text { fired. The effect of powder composition and firing temperature on } \\
\text { the densification and shape of the article are investigated. The } \\
\text { concept of vitrification is introduced. }\end{array}$ \\
\hline Ceramic Glazes & $\begin{array}{l}\text { Techniques for coloring and applying glazes to objects selected } \\
\text { by the student are utilized. An understanding of the chemistry, } \\
\text { synthesis and application of a glaze mixture is developed. }\end{array}$ \\
\hline Viscosity of Suspensions & $\begin{array}{l}\text { Viscosity is important in many ceramic forming techniques. The } \\
\text { experiment provides experience in the principles and } \\
\text { measurement of viscosity in liquids and particulate suspensions. }\end{array}$ \\
\hline X-ray Diffraction & $\begin{array}{l}\text { The technique of x-ray diffraction and its use for the } \\
\text { identification of crystalline phases is introduced. }\end{array}$ \\
\hline Glass Melting and Casting & $\begin{array}{l}\text { The melting, casting, and annealing of glasses are studied. The } \\
\text { use of glass melting and casting equipment, batch calculations for } \\
\text { glass compositions, and annealing of the cast material are } \\
\text { important features of the experiment. Experience in the use of a } \\
\text { polariscope to monitor residual stresses is also provided. }\end{array}$ \\
\hline Crystallization of Glasses & $\begin{array}{l}\text { Heating schedules for glass crystallization are studied. The } \\
\text { crystallization process is characterized using x-ray diffraction and } \\
\text { differential thermal analysis. }\end{array}$ \\
\hline Refractive Index of Glass & $\begin{array}{l}\text { Measurement of the refractive index of glasses by the Becke line } \\
\text { test. }\end{array}$ \\
\hline
\end{tabular}

decomposition of a salt $\left(\mathrm{MgCO}_{3}\right)$, (b) solid-state reaction to form a complex oxide $\left(\mathrm{BaTiO}_{3}\right)$, and (c) precipitation of $\mathrm{TiO}_{2}$ from solution. Thermal analysis techniques, thermogravimetric analysis (TGA) and differential thermal analysis (DTA), are used to characterize the kinetics of the solid state reactions and $\mathrm{x}$-ray diffraction is used to identify the phases formed. Particle size is analyzed by optical methods.

2. Stabilization and Characterization of Particulate Suspensions The formation of ceramic green bodies from concentrated suspensions of fine particles (slurries) is a widely used industrial process. The laboratory investigates two important methods by which suspensions are stabilized: electrostatic repulsion between adsorbed surface charges and electrosteric repulsion between adsorbed ionic polymers (polyelectrolytes). The properties of the suspensions are characterized by electro-kinetic measurements of the zeta-potential and by 
determining the viscosity. The influence of particle concentration, $\mathrm{pH}$, and polyelectrolyte concentration on the viscosity of aluminum oxide suspensions is investigated.

3. Forming of Ceramics

Tape casting and injection molding are investigated for the formation of ceramic green bodies. These methods complement the methods of die-pressing, slip casting, and extrusion studied at the sophomore level to provide a broad background in common ceramic forming methods. The use of polymeric additives, vital to many ceramic forming methods, is considered. Tape cast sheets and injection molded bars are prepared and fired. Binder burnout, often a critical step in ceramic forming, is also examined.

4. Sintering of Ceramics

Several key parameters that influence the sintering behavior of advanced ceramics are investigated. The variables include particle size, particle packing, and dopant concentration. Pellets having different particle size, packing homogeneity, and dopant levels are prepared and then fired under identical conditions. Fired density is measured to determine what effect heat has on the sintering process. Solid-state diffusion is used to incorporate a dopant, $\mathrm{Al}_{2} \mathrm{O}_{3}$, into a ceramic, $\mathrm{ZnO}$. The influence of dopant concentration on sintered density is determined in this laboratory and the sintered samples are also used in the following semester for characterization of microstructure.

Second Semester Junior Experiments in Ceramic Engineering at UMR:

The experiments in the first half of the second semester are devoted to characterization of crystal structure and microstructure by x-ray diffraction and microscopy. In the second half of the semester, the students undertake a project with the objective of producing a given target microstructure. The main features of the experiments are outlined below.

1. Microstructural Characterization by Optical and Scanning Electron Microscopy Techniques for preparing and etching polished sections of ceramics are developed. Using sintered pellets of undoped $\mathrm{ZnO}$ and $\mathrm{Al}_{2} \mathrm{O}_{3}$-doped $\mathrm{ZnO}$ prepared in the previous semester, the students section, grind, and polish samples. Polished sections are etched thermally to reveal grain boundaries. Polished, etched and fractured surfaces are examined by optical and scanning electron microscopy. The influence of the $\mathrm{Al}_{2} \mathrm{O}_{3}$ dopant on the grain growth is observed. Quantitative microscopy is performed by computer methods using imaging software (NIH Image or Scion Image) to determine average grain size, grain size distribution, and volume fraction porosity.

\section{X-Ray Diffraction}

Ability in the use of x-ray characterization methods is developed further with experiments in three basic areas. First, computer software (Scintag and Jade) is used in qualitative analysis to identify the composition of an unknown phase. Second, quantitative analysis by an internal standard method and by Rietveld analysis is used to determine the concentration of different phases in a two-phase mixture. Third, x-ray line broadening is used for the determination of the particle (crystal) size of a fine-grained powder. In addition to the analysis, the students get 
practical experience in the use of x-ray diffraction equipment by acquiring the diffraction patterns of their samples.

\section{Microstructure Design Project}

The objective of the project is to apply the practical knowledge gained from the processing and characterization laboratories to the fabrication of a ceramic with specific microstructural attributes. For a given starting powder, the target microstructure is given as a combination of minimum density (e.g., $97.5 \%$ of the theoretical), maximum required grain size (e.g., 2 micron), and purity level of the fabricated material. Commonly, students are given only the starting powders and can use any powder processing procedure to achieve the target microstructure by conventional sintering.

\section{Relationship of Junior Laboratories to the Lecture Courses}

First semester juniors are commonly enrolled in three Ceramic Engineering lecture courses to go along with the laboratory class described above. One is a thermal processing course in which diffusion, defect chemistry and diffusion-controlled processes such as solid state reaction, sintering and grain growth are considered. The second course is devoted to phase diagrams. Together, these two courses provide a firm basis for understanding how microstructures develop and how microstructural development is controlled by material and processing parameters. The third course is devoted to the basic elements of the engineering design process and covers topics such as planning and design of experiments, materials selection, engineering economics, safety and environmental issues. In the second semester, juniors are commonly enrolled in one ceramic engineering lecture course that is devoted to the basic principles and application of thermodynamics concepts to the solid state.

\section{Relationship Sophomore and Junior Laboratories to Other Ceramic Engineering Laboratories}

The laboratories at the sophomore and junior levels are designed to provide the students with a firm practical background in ceramic processing and microstructure characterization. As outlined in Table 1, one of the senior-level laboratories involves measurement of properties and studying the influence of microstructure on properties. Currently, the senior level laboratory is devoted to thermo-mechanical properties. In the future, it will consist of a set of parallel laboratories, each focussed on a related set of properties: thermo-mechanical, electrical and dielectric, or optical and magnetic. Students will choose one of the paths.

In addition to the senior level laboratory, the senior design project is a capstone to the undergraduate program. For senior design, the students are given the opportunity to apply the principles and practice of ceramic engineering to design and produce a ceramic component. For the 1999-2000 year, the senior class attempted to improve an existing industrial process. Four research groups explored different parts of the process in an attempt to make it more costeffective by improving the performance of the product, making the product from cheaper, more abundant raw materials, or using a lower firing temperature or a shorter firing time. 


\section{Summary}

Successful application of the principles of Ceramic Engineering requires the development of good laboratory practice. The properties of ceramics are strongly dependent on the microstructure. The use of particulate starting materials formed by compaction and sintering makes ceramic processing a complex process with many competing factors. Hence, the ability to manipulate several process parameters and determine their effect on the desirable properties of the finished product is vital. A strong background in practical laboratory work is one method for getting the practical education needed to be a successful ceramic engineer.

\section{Bibliography}

Further information about the principles, procedures and properties related to the experiments outlined in this paper can be found in several texts, including the following:

1. J. S. Reed, Principles of Ceramic Processing, $2^{\text {nd }}$ Edition, Wiley-Interscience, New York, 1995.

2. Engineered Materials Handbook, Volume 4: Ceramics and Glasses. ASM International, 1991.

3. W. D. Kingery (ed.), Ceramic Fabrication Processes, MIT Press, Cambridge, MA, 1963.

\section{MOHMAED N. RAHAMAN}

Mohamed N. Rahaman is a Professor of Ceramic Engineering at the University of Missouri-Rolla, where he has taught Ceramic Engineering courses at the undergraduate and graduate level for the last 13 years or so. His courses include two junior level laboratories devoted to processing and microstructural characterization of ceramics. Educated in England, Dr. Rahaman received B.A. and M.A. degrees in Physics from Cambridge University and a Ph.D. degree in Polymer Science from Sheffield University. In addition to his teaching duties, he is actively involved in ceramics research and has published a textbook and approximately 90 publications.

\section{WILLIAM G. FAHRENHOLTZ}

William G. Fahrenholtz joined the Ceramic Engineering Department at the University of Missouri-Rolla as an Assistant Professor in July, 1999. He received B.S. and M.S. degrees in Ceramic Engineering from the University of Illinois at Urbana-Champaign and a Ph.D. in Chemical Engineering form the University of New Mexico. His courses at the University of Missouri include the sophomore level laboratories in Ceramic Engineering. Dr. Fahrenholtz is active in ceramics research and has published over 25 technical papers. 